\title{
3 boyutlu yazıcı ile üretilen $A B S$ ve karbon fiber takviyeli ABS kompozitlerde üretim parametrelerinin mekanik özelliklere etkisi
}

\author{
Sare ÇELIKK, YıImaz GÜR* \\ Ballkesir Üniversitesi, Mühendislik Fakültesi, Makina Mühendisliği Bölümü, Çă̆ı̧s kampüsü, Balıkesir \\ Geliş Tarihi (Received Date): 15.05.2020 \\ Kabul Tarihi (Accepted Date): 30.09 .2020
}

$\ddot{O} \mathbf{z}$

Son yıllarda 3 boyutlu yazıcı teknolojisi ile parça üretimi hızla yaygınlaşmıştır. Geleneksel üretim yöntemlerine göre son derece karmaşık yapıya sahip parçalar çok klsa sürede, düşük maliyetle, hemen hemen hiçbir atık olmadan kolayca üretilebilmektedir. En yaygın olarak kullanılan 3 boyutlu yazıcı yöntemi ise ergiterek biriktirme yöntemidir $(E B Y)$. Ancak bu yöntemle sadece akrolonitril-butadien stiren (ABS) veya polilaktik asit (PLA) gibi termoplastikler kullanılarak üretim yapılabilmektedir. Son yıllarda, istenilen malzeme özelliklerinin elde edilmesi için takviyeli termoplastikler kullanilarak, EBY teknolojisi ile çalışan 3 üç boyutlu yazıcılar ile üretim yapılmaya başlanmıştır. Bu çalışmada ABS ve kırpılmış karbon elyafi takviyeli ticari ABS kompozit filamentler kullanılarak EBY teknolojili 3 boyutlu yazıcı ile üretilen ve farklı yazdırma yönleri ve farklı içyapı doldurma açılarına sahip çekme testi numunelerinin çekme testi sonuçları karşılaştırılmıştır. Çekme testi numuneleri ISO 527-2 Type-1A standardı referans alınarak 3 boyutlu yazıcıda yazdırılmıştır. Test numunelerinin içyapılarının 3 boyutlu yazıcı ile yazdırılması esnasında baskı kafasının izlediği yolun x ekseni ile yaptığı açılar $0^{\circ} / 90^{\circ}$ ile $+45^{\circ} /-45^{\circ}$ arasında değiştirilerek farklı içyapı doldurma açılarının mekanik özellikler üzerinde etkisi araştırılmıştır. Ayrıca mekanik özelliklerin test parçasının üretim platformu üzerine yerleştirme biçiminin etkisini tespit etmek amacıla da test numuneleri platform üzerine yatay ve yan kenar şeklinde yerleştirilerek yazdırllmıştır. Normal ABS, aynı doldurma açısına ve aynı yönde üretilen karbon fiber takviyeli ABS'den daha iyi mekanik özelliklere sahip olduğu görülmüştür.

Anahtar kelimeler: 3 boyutlu yazdırma, ABS, karbon fiber takviyeli ABS, katmanlı üretim.

Sare ÇELİK, scelik@balikesir.edu.tr, http://orcid.org/0000-0001-8240-5447

*Y1lmaz GÜR, ygur@balikesir.edu.tr, http://orcid.org/0000-0003-1709-1298 


\title{
The effect of printing parameters on mechanical properties of $\mathrm{ABS}$ and carbon fibre reinforced $\mathrm{ABS}$ composites fabricated with $3 \mathrm{D}$ printer
}

\begin{abstract}
In recent years, part production has become widespread with $3 D$ printer technology. Compared to traditional production methods, the highly complex parts can be easily produced in a very short time, at low cost, with virtually no waste. The most commonly used 3D printing method is fused deposition modelling (FDM) method. However, only thermoplastics such as Acrylonitrile-butadiene styrene (ABS) or polylactic acid (PLA) can be produced using this method. In recent years, using of reinforced thermoplastics has been started to obtain the desired mechanical properties with $3 D$ printing working with FDM technology. In this study, the tensile test results of tensile test samples fabricated by using the FDM $3 D$ printing method with ABS and short carbon fibre reinforced commercial ABS composite filaments with different build orientation and infill rates were compared. Tensile test samples were printed on a $3 D$ printer with reference to the ISO 527-2 Type-1A standard. During the printing of the internal structure of the test samples with a $3 D$ printer, the angles of the path of the printing head with the $x$ axis were changed between $0 / 90^{\circ}$ and $+45^{\circ} /-45^{\circ}$ and it was investigated whether different filling angles had an effect on the mechanical properties or not. In addition, in order to determine whether the orientation of the test samples on the build plate influence the mechanical properties or not, the test samples were placed and printed on the build plate horizontal and on side edge. It is found that neat ABS with the same orientation on the build plate and the same infill angles has better mechanical properties than carbon fibre reinforced $A B S$.
\end{abstract}

Keywords: $3 D$ printing, composite filament, carbon fibre reinforced $A B S$, additive manufacturing.

\section{Giriș}

İlk kez 1986 yılında Charles Hull tarafindan "stereolitografi ile üç boyutlu nesnelerin üretimi için bir cihaz" adı altında patenti alınan 3 boyutlu yazıcı teknolojisi hayatımıza girmiştir [1]. Bugün eklemeli üretim (EÜ) olarak bilinen teknolojinin en yaygın olarak kullanılan versiyonu ise ergiterek biriktirme yöntemidir (EBY). Bir nevi doğadaki katman katman büyüme konseptinin uygulaması diyebileceğimiz bu yöntemin patenti ise S. Scott Crump tarafından 1992 yılında alınmıştır [2]. Eklemeli üretim ya da daha yoğun olarak bilinen adıyla 3 boyutlu (3B) baskı teknolojisi ile nispeten küçük boyutlardaki son derece karmaşık 3B parçaları katmanlı olarak bilgisayar destekli tasarım (BDT) modellerinden dijital olarak üretmek mümkün olmaktadır. Son yıllarda bu teknoloji çok çeşitli endüstrilerde giderek artan yoğunlukta kullanılmaya başlamıştır. Havacılık, uzay, otomobil sanayi, yap1 ve reklam sektörü, biyomühendislik, inşaat, makine mühendisliği, tıp, gıda, matematik, eğitim ve benzeri birçok alanda kullanımı örnek olarak verilebilir [3-7]. 
Günümüzde 3 boyutlu yazıcılar ile üretilen parçaların mekanik özelliklerinin arttırılabilmesi amacıyla üretim aşamasında kullanılan filamentlerin kompozit olarak üretilmesi yönünde bir eğilim bulunmaktadır. Bu çalışmada da içerisinde ağırlık olarak $\% 15$ oranında kırpılmış karbon fiber bulunan ve ticari olarak üretilen ABS filament kullanılmıştır. Bu filament kullanılarak üretilen çekme testi numunelerinin mekanik özellikleri nasıl etkilediği araştırılmış ve içerisinde takviye malzemesi bulunmayan sade ABS filamentten üretilen çekme testi numuneleri ile karşılaştırılarak aralarındaki farklılıklar sergilenmiştir. 3 boyutlu yazıcı ile test numunelerinin üretimi sırasında hem numunelerin üretim tablası üzerine iki farklı yönde yerleştirilmelerinin hem de içyapının doldurulması sırasında farklı doldurma yönü açılarının mekanik özellikler üzerinde nasıl etkili olduğu araştırılmıştır.

\section{Metod ve malzeme}

\subsection{Ergiterek biriktirme yöntemi (EBY)}

Bir eklemeli üretim teknolojisi olan ergiterek biriktirme yöntemi (EBY) üretim malzemesi olarak termoplastik polimer filamentleri kullanmaktadır. $\mathrm{Bu}$ filamentler günümüzde giderek çeşitlenmekte, acrylonitril butadiene styrene (ABS) veya polilaktik asit (PLA) bazlı, çelik, bakır, alüminyum, ahşap, karbon fiber, cam elyafı veya kevlar katk1lı kompozit olarak üretilebilmekte ve bu teknoloji sayesinde parça üretiminde kullanılabilmektedirler. EBY de termoplastik filament ekstrüzyon nozülünden çıkmadan hemen önce eritilmekte ve nozülün izlediği x-y düzlemi üzerindeki yol boyunca serilmekte ve o katmandaki işlem bitirildiğinde bir sonraki katmana geçilmek suretiyle 3 boyutlu parçanın üretimi tamamlanmaktadır. 3 boyutlu baskı işlemi sırasında kullanılan bazı parametreler üretilen parçanın mekanik özellikleri üzerinde etkili olmaktadır. Örneğin katman kalınlığının $300 \mu \mathrm{m}$ dan $100 \mu \mathrm{m}$ a indirilmesi parçanın yüzey kalitesini önemli derecede etkilemektedir. Ayrıca ektrüzyon nozül sıcaklığı da katmanların birbirine yapışması ve iyi bir ara yüz oluşturulması açısından önem arz etmektedir. Üretilecek parçanın üzerine serildiği üretim tablasının 1sıtılması özellikle ABS filamentin tablaya yapışması açısından son derece önemli olmakta aksi takdirde parça tabla üzerine tam yapışmayarak ya kenarlarından kalkmak suretiyle bükülmekte ya da tabladan koparak parça tamamen bozulmaktadır. Ayrıca baskı kafasının x-y düzlemi boyunca hareket hızı, parçanın tabla üzerinde konumlandırma biçimi, parçanın içini doldurma için kullanılan desen ve bu doldurma işlemini yaparken baskı kafasının nasıl hareket edeceği gibi birçok parametre üretilen parçanın mekanik özellikleri üzerinde etkili olmaktadır[8,10].

Ergiterek biriktirme modellemesi yöntemi kullanılarak üretilen çekme test numunesine ait şematik gösterim Şekil 1 de verilmiştir.

\subsection{Kullantan malzemeler ve donanım}

Çekme testi numunelerinin 3 boyutlu yazıcı ile basılması sırasında iki farklı termoplastik filament kullanılmıştır. Bunlardan biri içerisinde ağırlık olarak \%15 kırpılmış karbon fiber bulunan ticari Frosch marka takviyeli ABS filament diğeri ise Octave ABS filamentdir. Filamentlerin çapı $1.75 \mathrm{~mm}$ dir. Kırpılmış karbon fiber takviyeli ABS filament son derece aşındırıcı bir malzeme olduğu için 3 boyutlu baskı sırasında sertleştirilmiş çelikten yapılmış $0.4 \mathrm{~mm}$ delik çaplı nozül kullanılmıştır. Aynı nozül ABS filamentten yapılan test numunesi üretiminde de kullanılmıştır. Kullanılan 3 boyutlu yazıcı ise 1sıtmalı üretim tablasına sahip çift kafalı Flashforge Creator dur. Dilimleme 
yazılımı olarak ise lisansa ihtiyaç duymayan genel kullanımına açık MakerWare ${ }^{\mathrm{TM}}$ 2.4.1.24 programı kullanılmıştır.

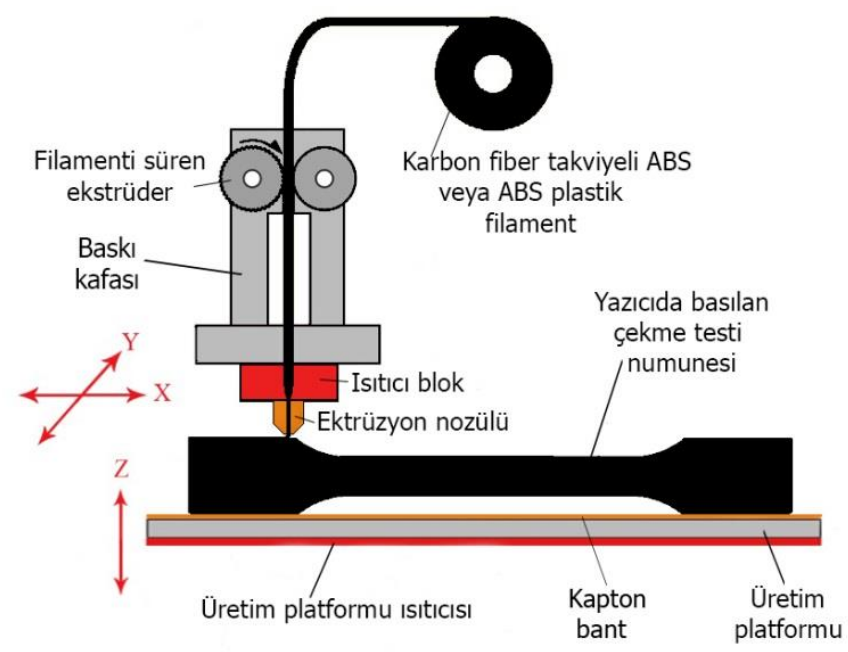

Şekil 1. Ergiterek biriktirme yöntemi (EBY) [11].

\section{3. Çekme testi numunelerinin 3 boyutlu yazıcıda üretilmesi}

Çekme testi numunelerinin 3 boyutlu yazıcıda üretilmesi sırasında Şekil 2 de boyutları verilmiş olan ISO-527-2-tip-1A standardı kullanılmıştır. Kırpılmış karbon fiber takviyeli ve katkısız ABS'den yapılan numunelerin 3 boyutlu yazıcıda basılması esnasinda yazdırma parametreleri tamamen aynı kullanılmıştır. Örneğin her iki malzeme çeşidi için de baskı sıcaklığ $224{ }^{\circ} \mathrm{C}$, 1sıtmalı üretim tablası sıcaklığ $100{ }^{\circ} \mathrm{C}$, yazdırma hızı dış kontur için $20 \mathrm{~mm} / \mathrm{s}$, iç konturlar için $30 \mathrm{~mm} / \mathrm{s}$, kontur sayısı 3, iç yapı doldurma hızı $30 \mathrm{~mm} / \mathrm{s}$, ilk katmanı yazdırma hızı 10 mm/s, katman kalınlığı $150 \mu \mathrm{m}$, nozül delik çap1 $400 \mu \mathrm{m}$, filament çap1 $1.75 \mathrm{~mm}$ olarak alınmıştır.

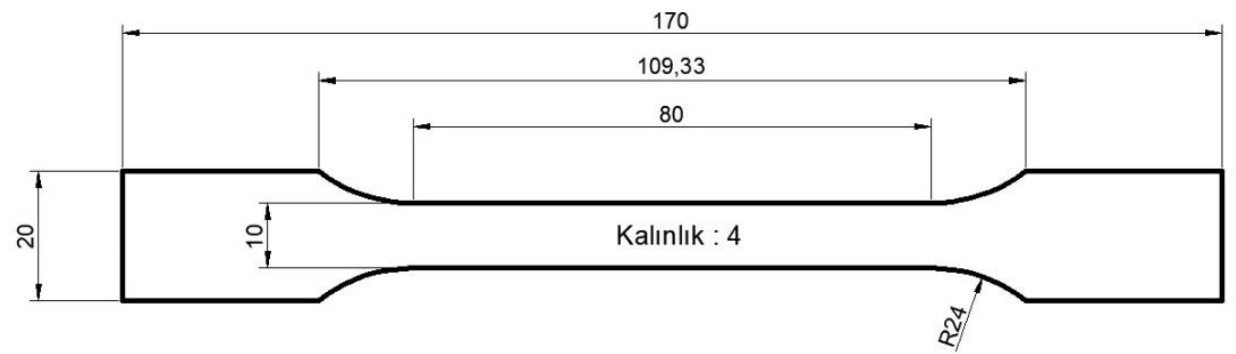

Şekil 2. ISO-527-2-tip-1A standardındaki çekme testi numune boyutları.

Çekme testi numunelerinin 3 boyutlu yazıcıda üretimi sırasında numunelerin üretim tablası üzerine farklı yönlerde yerleştirilmelerinin mekanik özellikler üzerindeki etkilerini görmek amaciyla da üretilecek test numuneleri tabla üzerine iki farklı yönde yerleştirilmişlerdir. Şekil 3 de test numunelerinin tabla üzerindeki yerleştirme biçimleri görülmektedir. Birinci yerleştirme biçimi 20x170 mm kesite sahip alt yüzeyin üretim tablasına paralel olduğu ve yatay diye isimlendirilen konumlandırma yönü, ikincisi ise 4x170 mm lik kesit alanına sahip yan kenar yüzeyinin üretim tablasına paralel olduğu ve yan kenar diye isimlendirilen konumlandırma yönüdür. Her bir konumlandırma yönü için içyapı doldurma açıları Şekil 4 de görüleceği üzere $+45^{\circ} / 45^{\circ}$ ve $0^{\circ} / 90^{\circ}$ olarak uygulanmıştır. Burada $0^{\circ}$ nin anlamı üretim tablasının x eksenine paralel olarak içyapının 
doldurulması, $90^{\circ}$ ise içyapının üretim tablasının x eksenine dik yönde doldurulmasıdır. 3 boyutlu yazdırma esnasında bir katmanda test numunesinin içyapısını doldurma açısı $0^{\circ}$ olurken bir sonraki katmanda içyapı doldurma açısı $90^{\circ}$ olmaktadır (Şekil 4a).

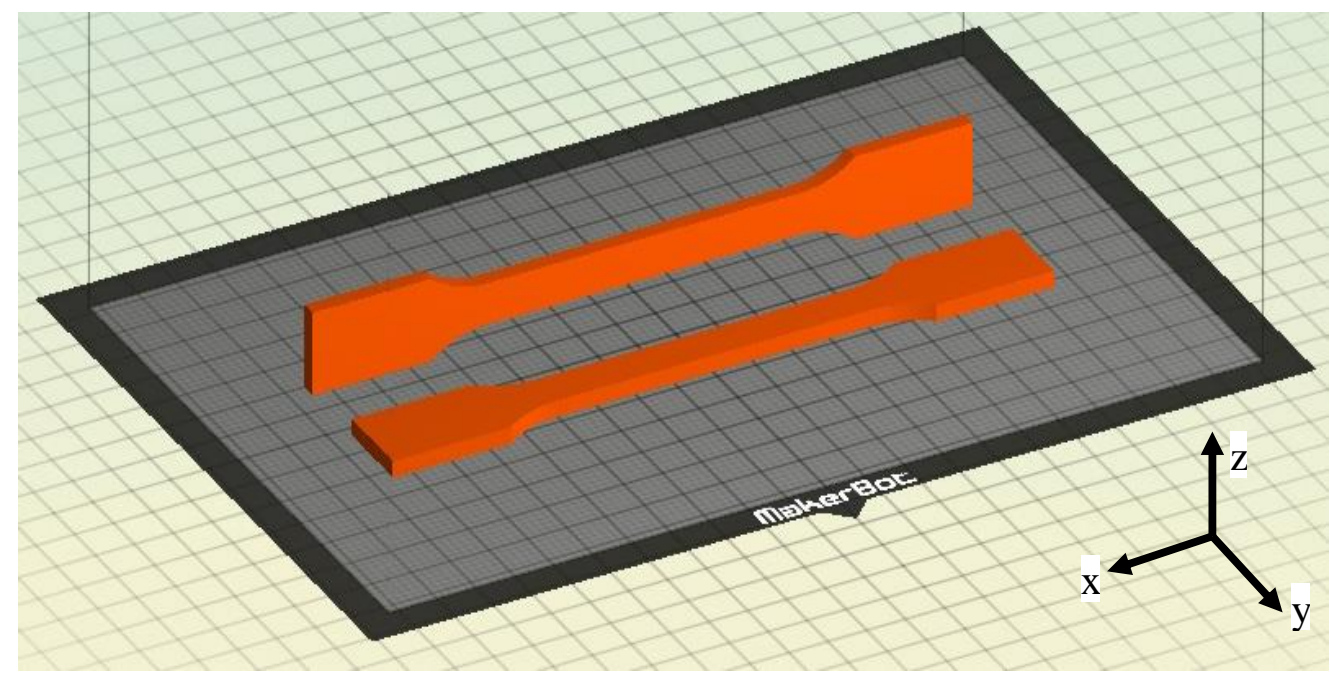

Şekil 3. Çekme testi numunelerinin üretim tablası üzerine yerleştirilme yönleri.

Çekme testi içyapı doldurma açısının $+45^{\circ}$ olması durumunda ise baskı kafası üretim tablasının x-y düzlemi dikkate alındığında saatin dönüş yönünün tersi yönünde $+45^{\circ},-45^{\circ}$ dikkate alındığında ise saatin dönüş yönünde $45^{\circ}$ olacak şekilde doldurulmaktadır. Yine bir katmanda doldurma açısı $45^{\circ}$ olurken bir sonraki katmanda ise $-45^{\circ}$ olmaktadır (Şekil 4b). Çekme testi numunelerinin içyapıları \%100 dolulukla üretilmiştir.

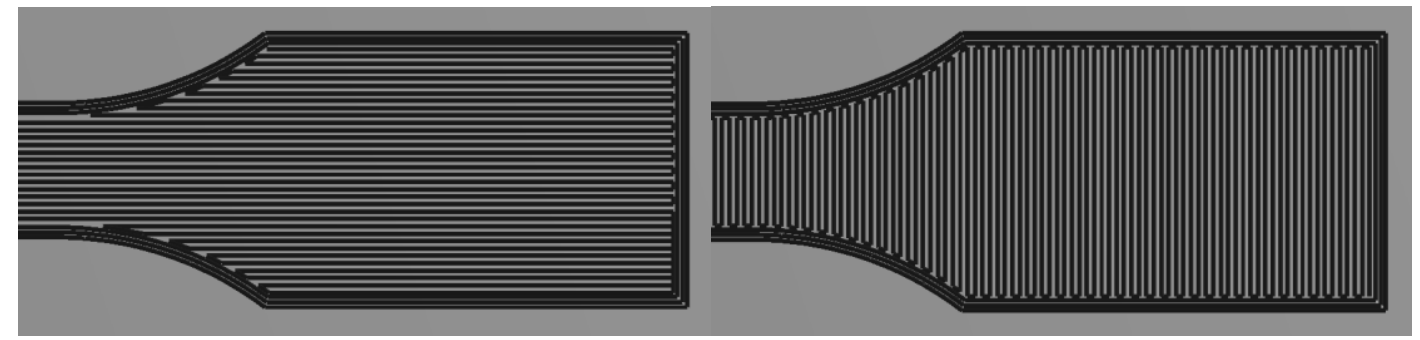

a) İç yapı doldurma açısı : $0^{\circ}$

$90^{\circ}$

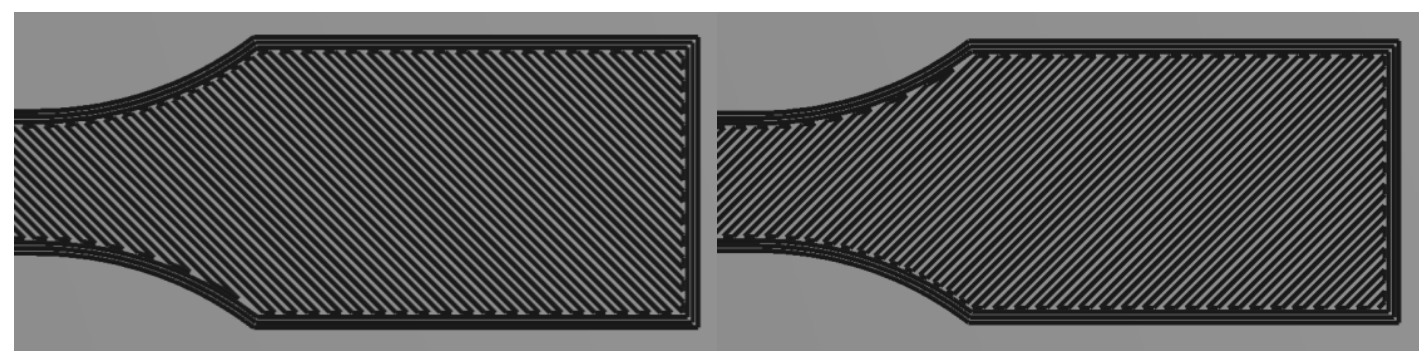

b) İç yapı doldurma açısı : $+45^{\circ}$

$-45^{\circ}$

Şekil 4. Çekme testi numunelerinin iç yapı doldurma açıları a) $0 \% 90^{\circ}$ b) $+45^{\circ} / 45^{\circ}$

\section{Bulgular ve tartışma}

Bu bölümde 3 boyutlu yazıcı ile üretilen, farklı üretim yönlerine (yatay ve yan) ve farklı içyapı doldurma açılarına $\left(0^{\circ} / 90^{\circ}\right.$ ve $\left.+45 /-45^{\circ}\right)$ sahip hem ABS ve hem de karbon fiber takviyeli ABS çekme testi numunelerinin değerlendirmesi yapılmıştır. Şekil 5 de sözü 
edilen numunelerin çekme testi sonrası kırılma bölgeleri, üretim yönleri ve içyapı doldurma açıları görülmektedir.

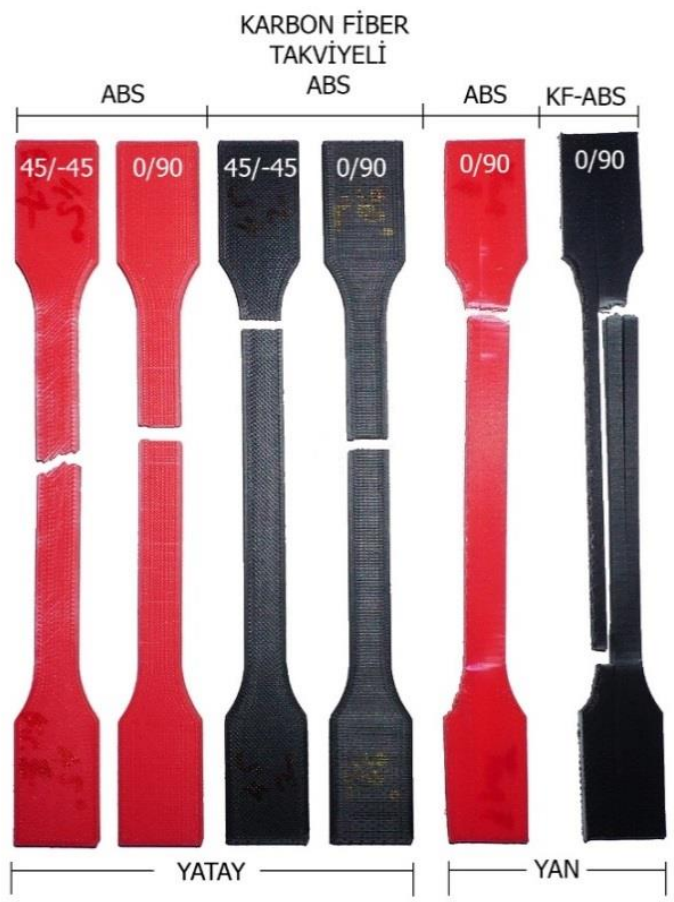

Şekil 5. 3 boyutlu yazıcıda basılmış numunelerinin çekme testi sonrası görüntüleri

EBY yöntemi kullanılarak 3 boyutlu yazıcıda üretilen polimer esaslı parçaların mekanik özelliklerinin üretim tablası üzerinde nasıl konumlandırıldıklarına ve içyapı doldurma açılarına bağlı olarak nasıl değiştiği, yapılan çekme testi sonuçlarına bakılarak değerlendirilmiştir. Katkısız ABS ve karbon fiber takviyeli ABS malzemeden üretilmiş numunelerin çekme testi sonucunda elde edilen gerilme-şekil değiştirme grafikleri sırası ile Şekil 6 ve Şekil 7 de verilmiştir.

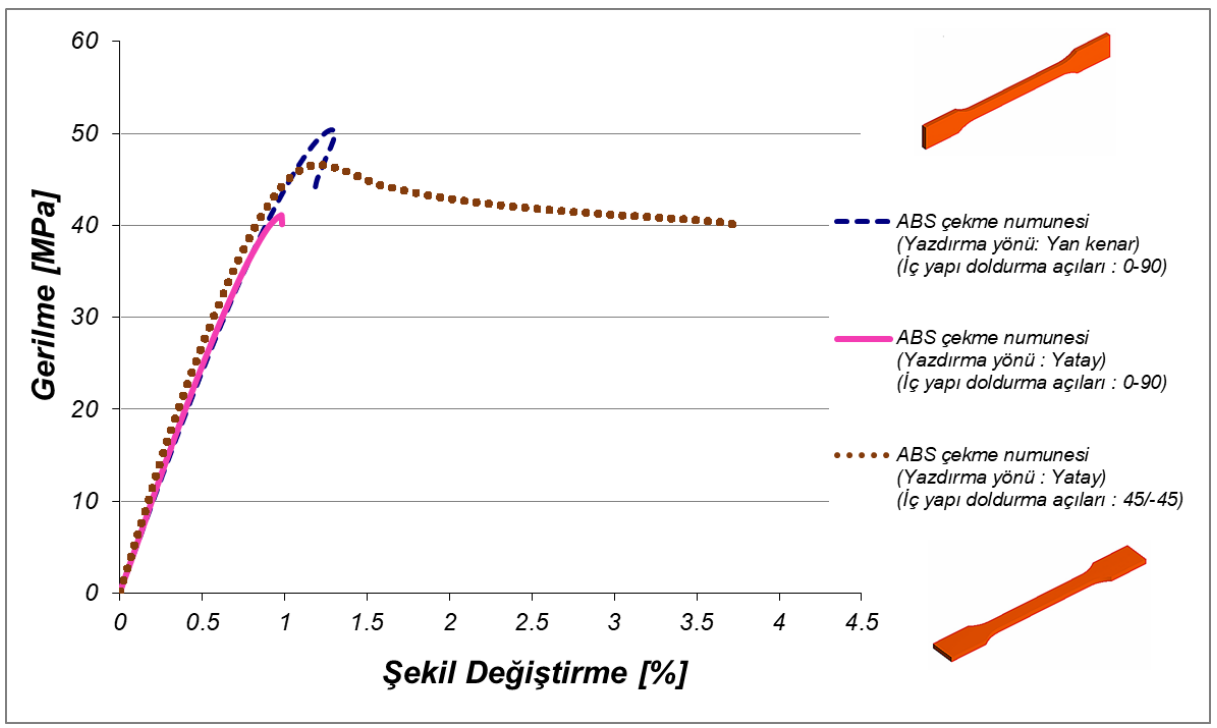

Şekil 6. ABS çekme testi numunelerinin farklı yön ve açılara göre gerilme-şekil değiştirme eğrileri. 


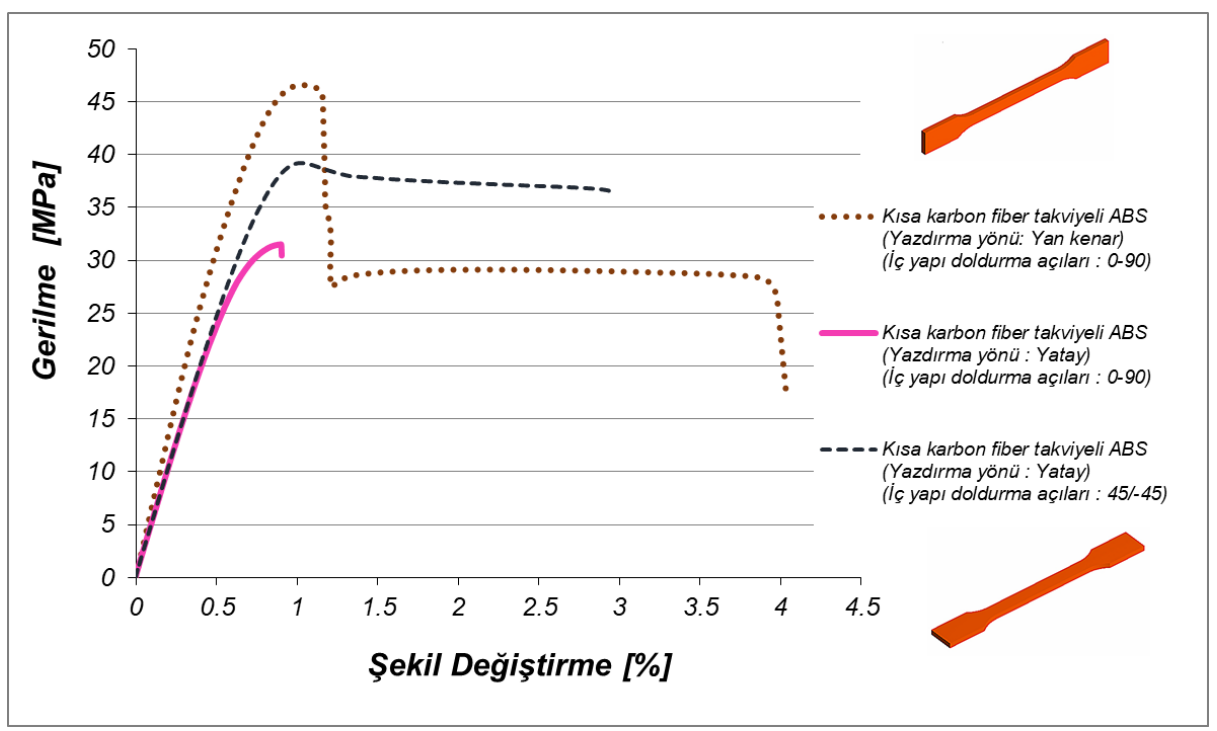

Şekil 7. Karbon fiber takviyeli ABS çekme testi numunelerinin farklı yön ve açılara göre gerilme-şekil değiştirme eğrileri.

Şekil 6 ve 7 de görüldüğü gibi başlangıçta her iki malzeme türünün de gerilme-şekil değiştirme eğrilerinin akma gerilmesine kadar Hooke yasasına uygun davranış sergilediği görülmektedir. Şekil 6 daki ABS polimerden 3 boyutlu yazıcı ile farklı içyapı doldurma açısı ve farklı yönde (yatay ve yan kenar) üretilmiş test parçalarının gerilme-şekil değiştirme eğrileri incelendiğinde, yan kenar olarak üretilen parçanın çekme dayanım değerinin çok daha yüksek olduğu $(50,388 \mathrm{MPa})$ görülmektedir. Yatay ve içyapı doldurma açıları $+45^{\circ} /-45^{\circ}$ olan numunenin çekme dayanımı daha düşüktür $(46,623 \mathrm{MPa})$ ancak şekil değiştirme miktarı daha fazladır. En düşük çekme dayanımı $(41,077 \mathrm{MPa}) 0^{\circ} / 90^{\circ}$ içyapı doldurma açılarına sahip ve yatay olarak üretilen numunede elde edilmiştir. İçyapı doldurma açısı ve üretim yönü farklılıkları, aynı şekle sahip parçalar için mekanik davranışların değişmesine yol açmıştır. $\mathrm{Bu}$ sonuçlar, literatürdeki çalışmalarla desteklemektedir [12]. Yazdırma yönü ve doldurma açısına bağlı çekme dayanım değerlerindeki sıralama, Şekil 7 de görüldüğü gibi \%15 karbon fiber takviyeli ABS kompozit malzemeden üretilmiş numuneler için de geçerlidir.

Şekil 8 de ise karşılaştırmak amacı ile hem ABS hem de karbon fiber takviyeli ABS den üretilmiş olan çekme testi numunelerinin tamamının gerilme-şekil değiştirme diyagramı görülmektedir. Şekil 8 incelendiğinde, ABS ve karbon fiber takviyeli ABS malzemelerin uygulanan gerilmeye bağlı, şekil değiştirme karakteristiklerinin, yazdırma yönlerine ve içyapı doldurma açılarına bağlı olarak aynı olduğu görülmektedir. Karbon fiber takviyeli ABS kompozitlerin çekme dayanım değerleri ise aynı yazdırma yönlerinde daha düşüktür. ABS katmanlar arası ve katmanlar içinde birbirlerine daha sıkı tutunurken karbon fiber takviyeli filamentlerde bağlar zayıflamaktadır [13]. Çekme testlerinden sonra alınan görüntülerde özellikle yan kenar olarak üretilen karbon takviyeli ABS'de gözlenen ayrılmalar karbon fiber ile polimer arasında iyi bir ara yüzeyin oluşamadığını doğrulamaktadır (Şekil 5). Buna rağmen yan kenar üretilen karbon takviyeli ABS, yatay üretilen $0^{\circ} / 90^{\circ}$ içyapı doldurma açılı ABS den daha yüksek, +45/-45 içyapı doldurma açılı ABS ile yaklaşık aynı dayanıma sahiptir. 


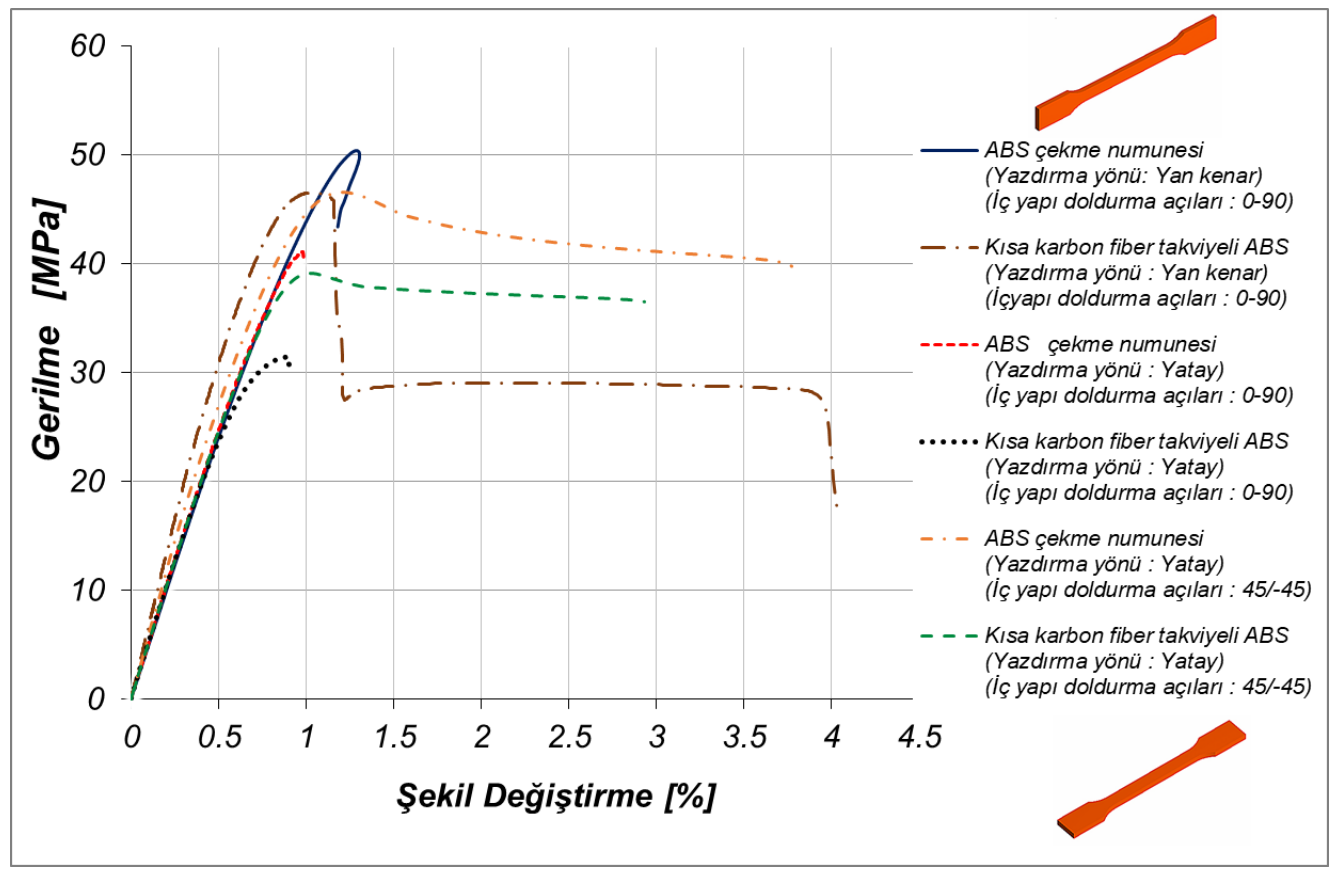

Şekil 8. ABS ve \%15 karbon fiber takviyeli ABS çekme testi numunelerinin farklı yön ve açılara göre Gerilme-Şekil değiştirme eğrileri.

Çekme deneyleri sonrası kırılma yüzeyleri incelenmiştir. Optik görüntülerden anlaşılacağ1 üzere, yatay ve yan kenar yönünde, $0^{\circ} / 90^{\circ}$ içyap1 doldurma açıları ile karşılaştırılan $+45^{\circ} /-45^{\circ}$ içyapı doldurma açılarına sahip numuneler, $0^{\circ} / 90^{\circ}$ ye göre düşük gözenekliliğe sahip olduğu gözlenmiştir.
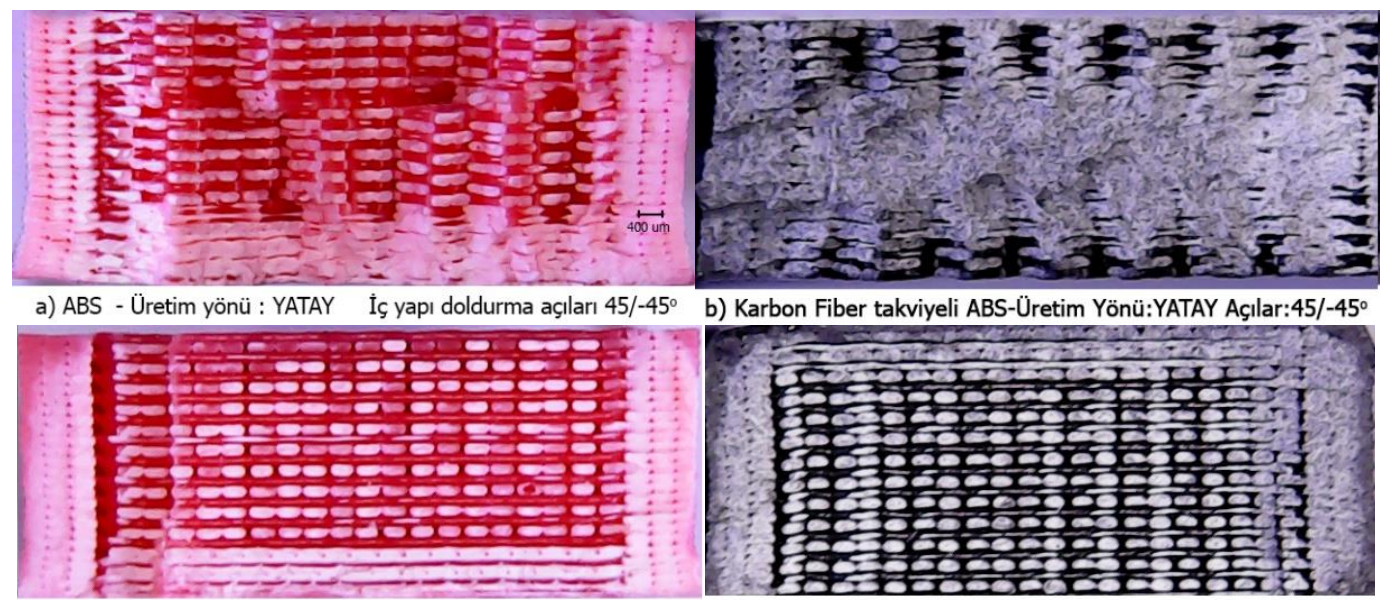

c) ABS - Üretim yönü : YATAY İç yapı doldurma açıları 0/90

d) Karbon Fiber takviyeli ABS-Üretim yönü: YATAY Açılar: $0 / 90^{\circ}$
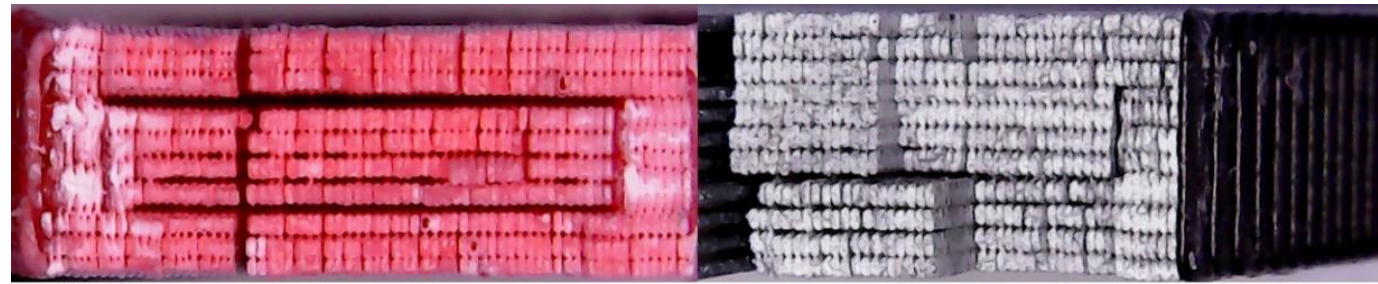

e) ABS Üretim Yönü: YAN İç yapı doldurma açıları : $0 / 90^{\circ}$

f) Karbon Fiber takviyeli ABS Üretim yönü: YAN Açılar : $0 / 90^{\circ}$

Şekil 9. Numunelerin çekme testi sonrası kırılma yüzeylerinin mikroskop görüntüleri

$\mathrm{Bu}$ durum, Şekil 6,7 ve 8 'de verilen yatay yazdırma yönüne sahip $+45^{\circ} / 45^{\circ}$ açılı numunelerde elde edilen yüksek mekanik mukavemeti de doğrulamaktadır (bakınız Şekil 
9. a-d). Ayrıca, genellikle yan kenar yönünde üretilmiş numunelerin ara katman yapısı, bu versiyonda daha fazla katman basılması gerektiği için, aynı içyapı doldurma açısına sahip yatay olarak üretilenden daha iyi sıkıştırma ve yapışma özelliğine sahiptir. Ancak katman yapışma yönü daha fazla yükleme kuvveti taşıyan yükleme yönüne diktir. Özellikle karbon fiber takviyeli ABS'nin zayıf ara tabaka yapışması söz konusu olmasına rağmen dayanım değeri daha yüksek çıkmıştır (Şekil 9. e-f).

\section{Sonuçlar}

Bu çalışmada, ABS ve \%15 karbon fiber takviyeli ABS kompozitin çekme dayanımı özellikleri, 3 boyutlu yazıcı ile üretilmesinde kullanılan parametrelerin etkileri, yani üretim yönü ve içyapı doldurma açısı dikkate alınarak değerlendirilmiştir. Temel araştırma bulguları aşağıdaki gibi özetlenmiştir;

i) Farklı yazdırma yönü ve doldurma açıları ile üretilen hem ABS hem de karbon fiber takviyeli ABS kompozitlerde en iyi çekme dayanım değeri yan yazdırma yönüne sahip numunelerde elde edilmiştir. Yatay yönde ise, $+45^{\circ} /-45^{\circ}$ içyap1 doldurma aç1larına sahip numunenin çekme dayanımı yan yöne göre daha düşüktür, ancak şekil değiştirme miktarları daha fazladır. En düşük çekme dayanımı yatay yönde $0^{\circ} / 90^{\circ}$ içyapı doldurma açılarına sahip numunelerde elde edilmiştir.

ii) Normal ABS, aynı doldurma açısına ve aynı yönde üretilen karbon fiber takviyeli ABS'den daha iyi 3 boyutlu yazdırılma yeteneğine sahiptir. ABS numuneler karbon fiber takviyeli ABS ile karşılaştırıldığında daha iyi mekanik özelliklere sahip olduğu görülmüştür. Bunun nedeni ABS ile karbon fiberin zayıf ara katman bağları nedeniyle daha düşük mekanik dayanıma sahip olmasıdır. Ayrıca, yan kenar yönünde ABS numuneler en yüksek çekme dayanımına sahiptir.

iii) Çekme deneylerinden sonra numunelerin kırılma yüzeyleri analiz edilmiştir. Karbon fiber takviyeli ABS kompozit parçaların düşük mekanik özellikleri, saf ABS ile karşılaştırıldığında gözeneklilik, katmanlar arasındaki zayıf yapışma gibi kusurların varlığı nedeniyle iyi bir ara yüzey oluşturamamasından kaynaklanmıştır.

\section{Kaynaklar}

[1] Hull, C.W., (1986) Apparatus for production of three-dimensional objects by stereolithography. U.S.Patent 4,575,330 (Publication Date: 3/11/1986; Filing Date 8/8/1984). http://www.google.com/patents/US4575330. (10.06.2014)

[2] Crump, S.S., U.S. Patent 5121329, Apparatus and method for creating three dimensional objects, U.S.Class: 364/468, ASSIGNEES: Stratasys, Inc., Minneapolis, MN,(Filed: Oct. 30, 1989 - Date of Patent : Jun. 9, 1992).

[3] Liu, Z.G., Wang Y.Q., Wu, B.C., Cui, C.Z., Guo Y., Yan C., A critical review of fused deposition modeling 3D printing technology in manufacturing polylactic acid parts, Int. J. Adv. Manuf. Technol., 102, 2877-2899, (2019).

[4] Wang, X., Jiang M., Zhou Z.W., Gou J.H., Hui D., 3D printing of polymer matrix composites: a review and prospective, Compos B. Eng., 110, 442-458, (2017). 
[5] Mohammed, J.S., Applications of 3D printing technologies in oceanography, Methods Oceanogr, 17, 97-117, (2016).

[6] Thompson, M.K., Moroni, G, Vaneker, T., Fadel, G., Campbell, R.I., Gibson, I., et al., Design for additive manufacturing trends, opportunities, considerations, and constraints, CIRP Annals- Manufacturing Technology, 65, 737-760, (2016).

[7] Uzun, M., Gür, Y., Usca, Ü.A., Manufacturing of new type curvilinear tooth profiled involute gears using 3D printing, J. BAUN Inst.Sci.Technol., 20(1), 278-286, (2018).

[8] Song, Y., Li, Y., Song, W., Yee, K., Lee, K.Y., Tagariell, V.L., Measurements of the mechanical response of unidirectional 3D printed PLA, Materials \& Design, 123, 154-164, (2017).

[9] Tianyum, Y., Juan, Y., Zichen, D., Kai, Z., Yongbin, Ma., Huajiang, O., Tensile failure strength and separation angle of FDM 3D printing PLA material: experimental and theoretical analyses, Composites Part B Engineering, 188, 107894, (2020).

[10] Dizon, J.R.C., Espera, A.H., Chen, Q., Advincula, R.C., Mechanical characterization of 3D-printed polymers, Additive Manufacturing, 20, 44-67, (2018).

[11] Gür, Y., Mathematical Modelling and Additive Manufacturing of a Gyroid, Machado, J.A.T., Özdemir, N., Baleanu,D.(Eds.), Mathematical Modelling and Optimization of Engineering Problems, Springer Nature Switzerland AG, Vol. 30, 187-196, (2020).

[12] Liu, Z., Lei, Q., Xing, S., Mechanical characteristics of wood, ceramic, metal and carbon fiber-based PLA composites fabricated by FDM, J. Mater. Res. Technol., 8(5), 3741-3751, (2019).

[13] Sezer, H.K., Eren, O., Börklü, H.R., Özdemir, V., Karbon fiber takviyeli polimer kompozitlerin ergiyik biriktirme yöntemi ile eklemeli imalatı: fiber oranı ve yazdırma parametrelerinin mekanik özelliklere etkisi, Journal of the Faculty of Engineering and Architecture, 34:2, 663-674 (2019). 